\title{
The influence of metabolic syndrome in the outcomes of colorectal cancer patients
}

\author{
André Goulart ${ }^{\mathrm{a}, \mathrm{b}, *}$, Ana Varejão ${ }^{\mathrm{b}}$, Fernanda Nogueira ${ }^{\mathrm{a}}$, Sandra Martins ${ }^{\mathrm{a}, \mathrm{b}}$, \\ António Mesquita-Rodrigues ${ }^{\mathrm{a}}$, Nuno Sousa ${ }^{\mathrm{b}}$, Pedro Leão ${ }^{\mathrm{a}, \mathrm{b}}$ \\ ${ }^{a}$ General Surgery, Hospital de Braga, Portugal \\ ${ }^{\mathrm{b}}$ Life and Health Science Research Institute (ICVS), School of Medicine University of Minho, Braga, Portugal
}

\section{A R T I C L E I N F O}

Keywords:

Metabolic syndrome

Colorectal cancer

\begin{abstract}
A B S T R A C T
Aims: Determine the influence of metabolic syndrome and its different components in the outcomes of colorectal cancer surgery at 30 days.

Materials and methods: Prospective study that included all patients submitted to elective colorectal cancer surgery between August 2015 and August 2016 at Hospital de Braga. Clinical and laboratory parameters evaluated pre-operatively were: central obesity, blood pressure, fasting glucose, triglycerides levels and HDL cholesterol levels. Any complications during the first 30-days after surgery were recorded (readmission, reintervention, anastomotic dehiscence, morbimortality).

Results: One hundred and thirty-four patients were included. Metabolic syndrome was diagnostic in $40.7 \%$ of patients with the ATPIII definition, $67.5 \%$ with the AHA definition and $67.0 \%$ with the IDF definition. At 30 days after colorectal cancer surgery, 73.1\% patients don't have any complication, $15.7 \%$ have minor complications (grade I/II of Clavien-Dindo classification), 11.1\% have major complications (grade III/IV/V of Clavien-Dindo classification) and $1.5 \%$ have died from surgical complications (grade V of Clavien-Dindo classification). The statistic analysis didn't reveal any association between MS, or it's different components, and surgical outcomes.

Conclusion: This study seems to indicate that metabolic syndrome don't have any influence in surgical outcomes of colorectal cancer surgery.
\end{abstract}

(c) 2017 Diabetes India. Published by Elsevier Ltd. All rights reserved.

\section{Introduction}

The terms "metabolic syndrome" (MS) stand for a cluster of interrelated risk factors of metabolic origin that have been proved to predict a higher risk of atherosclerotic cardiovascular disease as well as type 2 diabetes mellitus expressing, this way, its clinical importance. With a prevalence of approximately $24,6-30.9 \%$ in Europe [1] the development of this syndrome appears to be directly related to abdominal obesity and insulin resistance [2].

Since its initial description (approximately 80 years ago) [1] many different definitions have been proposed by several institutions, but they all agree on the same basic components, namely hypertension, dyslipidemia, insulin resistance and central obesity.

\footnotetext{
* Corresponding author at: General Surgery, Hospital of Braga, 4701-965 Braga, Portugal.

E-mail address: andre.b.goulart@gmail.com (A. Goulart).
}

The most popular definitions are those from National Cholesterol Education Program - Third Adult Treatment Panel (NCEPATPIII), or just ATPIII, from 2001 [3], the International Diabetes Federation (IDF), from 2005 [4], and, finally, the American Heart Association/National Heart Lung and Blood Institute (AHA/NHLBI), from also 2005 [2].

Besides the cardiovascular consequences of the metabolic syndrome, in several cohort studies and meta-analyses, this entity has been proven to increase cancer risk in general [5,6] with major effects on the gastrointestinal tract, namely increasing the risk of non-neoplastic gastrointestinal disorders, precursor lesions and CRC itself [7]. This relationship between metabolic syndrome and the risk of colorectal cancer is at the moment supported by a large number of studies $[1,8,9]$, and this linkage is mainly explained by abdominal obesity and insulin resistance with a multifactorial mechanism of carcinogenesis involving the action of adipokines, inflammatory cytokines, adiponectin, leptin, IGF-1 and others [1].

Colorectal cancer represents an important health issue, as being the third most common cancer in men and the second in women worldwide ( $10.0 \%$ and $9.2 \%$ of the total, respectively) [10]. These 
numbers seem to be rising dramatically worldwide due to urbanization, aging, diet changes and lifestyle [11].

At least one study of our knowledge has already proved the deleterious influence of MS on CRC prognosis, with significantly shorter survival and higher recurrence and liver metastasizing rates, implying that MS is an important prognostic factor for CRC [12]. Moreover, this deleterious influence was also proved for the outcomes of CRC surgery at 30 days, showing a higher rate of postoperative complications and a longer hospital stay in patients classified with the AHA/NHLBI definition of MS. Also in this study from 2009, high blood pressure and high triglyceride levels were as well considered important risk factors for severe complications after CRC surgery, but only the presence of the cluster of metabolic abnormalities that constitute MS was proven to be an independent variable in the multivariate analysis, and not each individual component [13].

Concerning the influence of obesity in surgery outcomes, WC proved to be an independent risk factor for the development of parastomal hernia after permanent colostomy [14]. Another study published in 2013 proved that waist-hip-ration (as a measure of central obesity) had a significant influence in negative outcomes after CRC surgery, namely reoperation, medical complications, intraoperative complications and conversion to open approach, being this prediction effect superior to the one verified when measuring BMI and or WC [15]. Obesity was also associated with an increase in anastomotic leakage after rectal cancer resection [16].

Furthermore, a study concerning the financial implications of CRC surgery in obese patients has detected a significant increase in hospital expenses due to a higher rate of severe complications. The major contributors for these costs were wards stay, operations, and intensive care units [17].

The aim of this study is to determine the influence of MS and different components of MS (high fasting glucose, central obesity, high blood pressure, high triglycerides levels and low HDL cholesterol levels) in the outcomes of CRC surgery at 30 days (reintervention, readmission, dehiscence and morbimortality).

\section{Methods}

\subsection{Study oversight and patients inclusion}

This study included all the patients with a confirmed diagnosis of colorectal adenocarcinoma who underwent elective surgery at Hospital de Braga during August 2015 till August 2016. Patients who presented evidence of metastasis before or at surgery, necessity of removal of other organs due to tumor invasion, synchronous tumors or history of other malignant tumors within 5 years, history of familial adenomatous polyposis and hereditary non-polyposis colorectal carcinoma were excluded.

\subsection{Data collection}

At the first moment of evaluation, during pre-operative consultation, data were collected concerning patient's age, gender, history of arterial hypertension, diabetes mellitus, dyslipidemia, prior neoplasms, usual medication (with special concern for hypertension, diabetes, high triglycerides and low HDL cholesterol specific treatments) and family history of neoplasms. On the day prior to their admission to the hospital for surgery, the patients were requested to present themselves at Clinical Academic Center at Hospital de Braga for an anthropometric evaluation, carried out, all times, by the same nurse, which included height, weight and waist circumference measurement, as well as collection of blood samples for evaluation of fasting glucose, HDL cholesterol and triglycerides levels. During a period of 30 days following surgery, data about complications were collected and registered, namely morbimortality, readmission, reintervention and anastomotic dehiscence. Morbimortality was posteriorly classified according to Clavien-Dindo's classification [18].

\subsection{Statistical analysis}

Statistical analysis was performed using SPSS - Statistical Package for the Social Science Program, version 23.

Descriptive statistics are presented as absolute frequencies (n) and relative (\%) for categorical variables, and mean (M) and standard deviation (SD), or median (Mdn) and interquartile ranges, for quantitative variables, depending on whether or not symmetry of the distributions was ensured. The chi-square test was used to identify associations between dichotomous outcomes (morbimortality, dehiscence, reintervention and readmission) and the independent variables. When the maximum assumed $20 \%$ of cells with the expected frequency of less than 5 was exceeded, Fisher's test $(2 \times 2$ tables) was used. The Mann-Whitney test was used to compare the outcome measured on an ordinal scale (Morbimortality according to Clavien-Dindo classification) with the independent variables. Finally, logistic regressions were used to measure the risk of the independent variables on the dichotomous outcomes. The significance level for rejection of $\mathrm{H}_{0}$ was $5 \%$ $(\mathrm{p}<0.05)$

\subsection{Ethical issues}

The present study was approved by the Ethic Committee of Hospital de Braga. The investigators made sure to safeguard the anonymity and confidentiality of all the participants. A written informed consent was obtained from each patient.

\section{Results}

The present study included a sample of 134 patients with CRC diagnoses, with a mean age of 67.91 years old, 82 males and 52 females. 46 (40.7\% in 113 ) of these patients were diagnoses with MS according to the ATPIII definition, 79 (67.5\% in 117) according to the AHA definition and 71 (67.0\% in 106) according to the IDF definition. These data are shown in Table 1. We were not able to collect the necessary information for these diagnoses in some of the patients (ND in the table), most often by absence of the patient from the appointments with the nurse for measurement of anthropometric parameters and blood samples collection.

Table 1

Sample characterization; ND = No data.

\begin{tabular}{ll}
\hline & Statistics \\
\hline Age M (SD) & $67.91(12.94)$ \\
Gender n (\%) & \\
M & $82(61.2 \%)$ \\
F & $52(38.8 \%)$ \\
MS n (\%) & \\
ATPIII Definition & \\
No & $n=113$ \\
Yes & $67(59.3 \%)$ \\
ND & $46(40.7 \%)$ \\
AHA Definition & 21 \\
No & $\mathrm{n}=117$ \\
Yes & $38(32.5 \%)$ \\
ND & $79(67.5 \%)$ \\
IDF Definition & 17 \\
No & $\mathrm{n}=106$ \\
Yes & $35(33.0 \%)$ \\
ND & $71(67.0 \%)$ \\
\hline
\end{tabular}


Thirty days after CRC surgery, 98 patients (73.1\%) did not suffer from any complication. 11 patients were readmitted to the hospital, 10 patients suffered anastomotic dehiscence and 10 patients were again submitted to surgery. With a total morbimortality percentage of $26.9 \%$, only 2 deaths were registered during this period. Complications distribution according to Clavien-Dindo Classification and the previous data about 30 days after surgery outcomes are shown in Table 2.

Table 2

Sample surgical outcomes.

\begin{tabular}{ll}
\hline & $\mathrm{n}(\%)$ \\
\hline Readmission & $11(8.3 \%)$ \\
Dehiscence & $10(7.5 \%)$ \\
Reintervention & $10(7.5 \%)$ \\
Morbimortality & $36(26.9 \%)$ \\
Clavien-Dindo Classif. & \\
No complications & \\
Grade I & $98(73.1 \%)$ \\
Grade II & $8(6.0 \%)$ \\
Grade IIIa & $13(9.7 \%)$ \\
Grade IIIb & $3(2.2 \%)$ \\
Grade IVa & $6(4.5 \%)$ \\
Grade IVb & $1(0.7 \%)$ \\
Grade V & $3(2.2 \%)$ \\
Length of Hospital Stay Mdn (IQR) & $2(1.5 \%)$ \\
\hline
\end{tabular}

After applying chi-square tests, the results suggest no evidence of association between any of the MS definition diagnosis (or their different components) and the surgical outcomes studied, except for low HDL cholesterol levels by ATPIII definition (HDL $\mathrm{c}<40 \mathrm{mg} / \mathrm{dL}$ in men or $<50 \mathrm{mg} / \mathrm{dL}$ in women) as a predictor of morbimortality at 30 days, $(\mathrm{p}=0.037)$ (Table 3$)$.

Logistic regression was computed in order to calculate Odds ratio (OR) for the risk of having morbimortality having low HDL cholesterol (by ATPIII definition) as a predictor.

The risk of morbimortality for patients with low HDL cholesterol is 2.42 times increased when compared with patients with high HDL cholesterol $(95 \% \mathrm{CI}=[1.04,5.62])$. This result was statistically significant for $\mathrm{p}=0.039$ (Table 4 ).

As preforming Mann-Whitney Test for ordinal outcomes (Morbimortality according to Clavien-Dindo Classification) we were able to also stablish a statistically significant result, which states that patients with low HDL-cholesterol (by ATPIII definition)

Table 4

Logistic Model; In this case: Yes $=\mathrm{HDL}-\mathrm{C}<40 \mathrm{mg} / \mathrm{dL}$ in men or $<50 \mathrm{mg} / \mathrm{dL}$ in women and $\mathrm{No}=\mathrm{HDL}-\mathrm{C} \geq 40 \mathrm{mg} / \mathrm{dL}$ in men or $\geq 50 \mathrm{mg} / \mathrm{dL}$ in women.

\begin{tabular}{llll}
\hline & OR & $95 \%$ CI & p-value \\
\hline Low HDL cholesterol & & \\
No & 1 & 1 & 1 \\
Yes & 2.42 & $(1.04-5.62)$ & $\mathrm{p}=0.039$ \\
\hline
\end{tabular}

Table 3

Chi square tests results. relation between dichotomous outcomes and independent variables.

\begin{tabular}{|c|c|c|c|c|c|c|c|c|c|c|c|c|}
\hline & \multicolumn{3}{|c|}{ Readmission } & \multicolumn{3}{|c|}{ Reintervention } & \multicolumn{3}{|c|}{ Dehiscence } & \multicolumn{3}{|c|}{ Morbimortality } \\
\hline & No & Yes & $\begin{array}{l}\mathrm{p} \\
\text { value }\end{array}$ & No & Yes & $\begin{array}{l}\mathrm{p} \\
\text { value }\end{array}$ & No & Yes & $\begin{array}{l}\mathrm{p} \\
\text { value }\end{array}$ & No & Yes & $\mathrm{p}$ value \\
\hline MS ATPIII Definition & $43(93.5 \%)$ & $3(6.5 \%)$ & 0.456 & $42(91.3 \%)$ & $4(8.7 \%)$ & 0.361 & $\begin{array}{l}40 \\
(93.0 \%)\end{array}$ & $3(7 \%)$ & 0.854 & $\begin{array}{l}34 \\
(73.9 \%)\end{array}$ & $\begin{array}{l}12 \\
(26.1 \%)\end{array}$ & 0.790 \\
\hline Central Obesity (ATPIII Definition) & $44(91.7 \%)$ & $4(8.3 \%)$ & 0.787 & $45(93.8 \%)$ & $3(6.3 \%)$ & 0.462 & $\begin{array}{l}44 \\
(93.6 \%)\end{array}$ & $3(6.4 \%)$ & 0.861 & $\begin{array}{l}40 \\
(83.3 \%)\end{array}$ & $8(16.7 \%)$ & 0.056 \\
\hline High Triglycerides level (ATPIII Definition) & $42(91.3)$ & $4(8.7 \%)$ & 0.870 & $45(97.8 \%)$ & $1(2.2 \%)$ & 0.120 & $\begin{array}{l}41 \\
(97.6 \%)\end{array}$ & $1(2.4 \%)$ & 0.088 & $\begin{array}{l}33 \\
(71.7 \%)\end{array}$ & $\begin{array}{l}13 \\
(28.3 \%)\end{array}$ & 0.883 \\
\hline $\begin{array}{l}\text { Low HDL Cholesterol level (ATPIII } \\
\text { Definition) }\end{array}$ & $53(89.8 \%)$ & $\begin{array}{l}6 \\
(10.2 \%)\end{array}$ & 0.797 & $54(90.0 \%)$ & $\begin{array}{l}6 \\
(10.0 \%)\end{array}$ & 0.164 & $\begin{array}{l}49 \\
(89.1 \%)\end{array}$ & $\begin{array}{l}6 \\
(10.9 \%)\end{array}$ & 0.297 & $\begin{array}{l}38 \\
(63.3 \%)\end{array}$ & $\begin{array}{l}22 \\
(36.7 \%)\end{array}$ & .037 \\
\hline High Blood Pressure (ATPIII Definition) & $82(91.1 \%)$ & $8(8.9 \%)$ & 0.463 & $82(91.1 \%)$ & $8(8.9 \%)$ & 0.185 & $\begin{array}{l}77 \\
(90.6 \%)\end{array}$ & $8(9.4 \%)$ & 0.204 & $\begin{array}{l}62 \\
(68.9 \%)\end{array}$ & $\begin{array}{l}28 \\
(31.1 \%)\end{array}$ & 0.106 \\
\hline High Fasting Glucose (ATPIII Definition) & $44(91.7 \%)$ & $4(8.3 \%)$ & 0.787 & $45(93.8 \%)$ & $3(6.3 \%)$ & 0.462 & $\begin{array}{l}44 \\
(93.6 \%)\end{array}$ & $3(6.4 \%)$ & 0.861 & $\begin{array}{l}40 \\
(83.3 \%)\end{array}$ & $8(16.7 \%)$ & 0.056 \\
\hline MS AHA Definition & $73(92.4 \%)$ & $6(7.6 \%)$ & 0.595 & 75 (94.9\%) & $4(5.1 \%)$ & 0.963 & $\begin{array}{l}70 \\
(94.6 \%)\end{array}$ & $4(5.4 \%)$ & 0.529 & $\begin{array}{l}63 \\
(79.7 \%)\end{array}$ & $\begin{array}{l}16 \\
(20.3 \%)\end{array}$ & 0.054 \\
\hline Central Obesity (AHA Definition) & $44(91.7 \%)$ & $4(8.3 \%)$ & 0.787 & $45(93.8 \%)$ & $3(6.3 \%)$ & 0.462 & $\begin{array}{l}44 \\
(93.6 \%)\end{array}$ & $3(6.4 \%)$ & 0.861 & $\begin{array}{l}40 \\
(83.3 \%)\end{array}$ & $8(16.7 \%)$ & 0.056 \\
\hline High Triglycerides level (AHA Definition) & $42(91.3 \%)$ & $4(8.7 \%)$ & 0.870 & $45(97.8 \%)$ & $1(2.2 \%)$ & 0.120 & $\begin{array}{l}41 \\
(97.6 \%)\end{array}$ & $1(2.4 \%)$ & 0.088 & $\begin{array}{l}33 \\
(71.7 \%)\end{array}$ & $\begin{array}{l}13 \\
(28.3 \%)\end{array}$ & 0.883 \\
\hline $\begin{array}{l}\text { Low HDL Cholesterol level (AHA } \\
\text { Definition) }\end{array}$ & $85(90.4 \%)$ & $9(9.6 \%)$ & 0.595 & $87(91.6 \%)$ & $8(8.4 \%)$ & 0.095 & $\begin{array}{l}80 \\
(90.9 \%)\end{array}$ & $8(9.1 \%)$ & 0.095 & $\begin{array}{l}68 \\
(71.6 \%)\end{array}$ & $\begin{array}{l}27 \\
(28.4 \%)\end{array}$ & 0.319 \\
\hline High Blood Pressure (AHA Definition) & $\begin{array}{l}105 \\
(92.1 \%)\end{array}$ & $9(7.9 \%)$ & 0.771 & $\begin{array}{l}106 \\
(92.2 \%)\end{array}$ & $9(7.8 \%)$ & 0.232 & $\begin{array}{l}99 \\
(91.7 \%)\end{array}$ & $9(8.3 \%)$ & 0.246 & $\begin{array}{l}86 \\
(74.8 \%)\end{array}$ & $\begin{array}{l}29 \\
(25.2 \%)\end{array}$ & 0.380 \\
\hline High Fasting Glucose (AHA Definition) & $52(89.7 \%)$ & $\begin{array}{l}6 \\
(10.3 \%)\end{array}$ & 0.686 & $54(93.1 \%)$ & $4(6.9 \%)$ & 0.922 & $\begin{array}{l}50 \\
(94.3 \%)\end{array}$ & $3(5.7 \%)$ & 0.381 & $\begin{array}{l}44 \\
(75.9 \%)\end{array}$ & $\begin{array}{l}14 \\
(24.1 \%)\end{array}$ & 0.425 \\
\hline MS IDF Definition & $64(90.1 \%)$ & $7(9.9 \%)$ & 0.831 & $66(93.0 \%)$ & $5(7.0 \%)$ & 0.108 & $\begin{array}{l}60 \\
(92.3 \%)\end{array}$ & $5(7.7 \%)$ & 0.363 & $\begin{array}{l}54 \\
(76.1 \%)\end{array}$ & $\begin{array}{l}17 \\
(26.9 \%)\end{array}$ & 0.411 \\
\hline Central Obesity (IDF Definition) & $75(90.4 \%)$ & $8(9.6 \%)$ & 0.764 & $78(94.0 \%)$ & $5(6.0 \%)$ & 0.200 & $\begin{array}{l}71 \\
(92.2 \%)\end{array}$ & $6(7.8 \%)$ & 0.159 & $\begin{array}{l}65 \\
(78.3 \%)\end{array}$ & $\begin{array}{l}18 \\
(21.7 \%)\end{array}$ & 0.088 \\
\hline High Triglycerides level (IDF Definition) & $42(91.3 \%)$ & $4(8.7 \%)$ & 0.870 & $45(97.8 \%)$ & $1(2.2 \%)$ & 0.120 & $\begin{array}{l}41 \\
(97.6 \%)\end{array}$ & $1(2.4 \%)$ & 0.088 & $\begin{array}{l}33 \\
(71.7 \%)\end{array}$ & $\begin{array}{l}13 \\
(28.3 \%)\end{array}$ & 0.883 \\
\hline HDL Cholesterol level (IDF Definition) & $85(90.4 \%)$ & $9(9.6 \%)$ & 0.595 & $87(91.6 \%)$ & $8(8.4 \%)$ & 0.095 & $\begin{array}{l}80 \\
(90.9 \%)\end{array}$ & $8(9.1 \%)$ & 0.323 & $\begin{array}{l}68 \\
(71.6 \%)\end{array}$ & $\begin{array}{l}27 \\
(28.4 \%)\end{array}$ & 0.319 \\
\hline High Blood Pressure (IDF Definition) & $\begin{array}{l}105 \\
(92.1 \%)\end{array}$ & $9(7.9 \%)$ & 0.771 & $\begin{array}{l}106 \\
(92.2 \%)\end{array}$ & $9(7.8 \%)$ & 0.232 & $\begin{array}{l}99 \\
(91.7 \%)\end{array}$ & $9(8.3 \%)$ & 0.246 & $\begin{array}{l}86 \\
(74.8 \%)\end{array}$ & $\begin{array}{l}29 \\
(25.2 \%)\end{array}$ & 0.380 \\
\hline High Fasting Glucose (IDF Definition) & $52(89.7 \%)$ & $\begin{array}{l}6 \\
(10.3 \%)\end{array}$ & 0.686 & $54(93.1 \%)$ & $4(6.9 \%)$ & 0.922 & $\begin{array}{l}50 \\
(94.3 \%)\end{array}$ & $3(5.7 \%)$ & 0.381 & $\begin{array}{l}44 \\
(75.9 \%)\end{array}$ & $\begin{array}{l}14 \\
(24.1 \%)\end{array}$ & 0.425 \\
\hline
\end{tabular}


Table 5

Mann-Whitney Test Results. Relation between ordinal outcome (Morbimortality according to Clavien-Dindo classification) and Independent Variables.

\begin{tabular}{|c|c|c|c|c|c|}
\hline & \multicolumn{5}{|c|}{ Man- Whitney Test } \\
\hline & \multicolumn{5}{|c|}{ Morbimortality According to Clavien-dindo Classification } \\
\hline & \multicolumn{2}{|c|}{$\underline{\operatorname{Mdn}(\mathrm{IQR})}$} & \multirow[b]{2}{*}{$\mathrm{p}$ value } & \multirow[b]{2}{*}{$\mathrm{U}$} & \multirow[b]{2}{*}{ Z } \\
\hline & No & Yes & & & \\
\hline MS ATPIII Definition & $0(1)$ & $0(1)$ & 0.777 & 1503.00 & -0.283 \\
\hline Central Obesity (ATPIII Definition) & $0(2)$ & $0(0)$ & 0.091 & 1251.50 & -1.691 \\
\hline High Triglycerides level (ATPIII Definition) & $0(1)$ & $0(1)$ & 0.880 & 1680.00 & -0.151 \\
\hline Low HDL Cholesterol level (ATPIII Definition) & $0(0)$ & $0(2)$ & .033 & 1400.50 & -2.129 \\
\hline High Blood Pressure (ATPIII Definition) & $0(0)$ & $0(1)$ & 0.133 & 15670.50 & -1.504 \\
\hline High Fasting Glucose (ATPIII Definition) & $0(2)$ & $0(0)$ & 0.091 & 1251.50 & -1.691 \\
\hline MS AHA Definition & $0(2)$ & $0(0)$ & 0.067 & 1260.00 & -1.830 \\
\hline Central Obesity (AHA Definition) & $0(2)$ & $0(0)$ & 0.091 & 1251.50 & -1.691 \\
\hline High Triglycerides level (AHA Definition) & $0(1)$ & $0(1)$ & 0.880 & 1680.00 & -0.151 \\
\hline Low HDL Cholesterol level (AHA Definition) & $0(0)$ & $0(2)$ & 0.239 & 1312.00 & 0.239 \\
\hline High Blood Pressure (AHA Definition) & $0(2)$ & $0(1)$ & 0.398 & 881.00 & -0.845 \\
\hline High Fasting Glucose (AHA Definition) & $0(1)$ & $0(1)$ & 0.452 & 1685.50 & -0.752 \\
\hline MS IDF Definition & $0(1)$ & $0(1)$ & 0.538 & 1171.50 & -0.616 \\
\hline Central Obesity (IDF Definition) & $0(2)$ & $0(0)$ & 0.137 & 918.50 & -1.488 \\
\hline High Triglycerides level (IDF Definition) & $0(1)$ & $0(1)$ & 0.880 & 1680.00 & -0.151 \\
\hline HDL Cholesterol level (IDF Definition) & $0(0)$ & $0(2)$ & 0.239 & 1312.00 & -1.177 \\
\hline High Blood Pressure (IDF Definition) & $0(2)$ & $0(1)$ & 0.398 & 881.00 & -0.845 \\
\hline High Fasting Glucose (IDF Definition) & $0(1)$ & $0(1)$ & 0.452 & 1685.50 & -0.752 \\
\hline
\end{tabular}

present higher grades of complications, according to Clavien-Dion classification ( $\mathrm{Mdn}=0 ; \mathrm{IQR}=2 ; \mathrm{p}=0.033$ ), (Table 5).

\section{Discussion}

It is well known nowadays that MS is a risk factor for the development of CRC, as proven, between many others, by a large cohort study from 2006 [9] or by a recent meta-analysis (reporting 17 studies) from 2013 [8] being the pathophysiological mechanism pointed has responsible mostly related to insulin resistance and abdominal obesity [1]. This fact may perhaps explain the high incidence of MS (in all its definitions) in our sample (constituted only by CRC diagnosed patients) in comparison, for example, with a report that included 1433 inhabitants of Porto city (Portugal). In this study, the investigators obtained an estimated prevalence of MS of $24.0 \%$ with the ATPIII criteria, $37.2 \%$ with the AHA criteria and, $41.9 \%$ with the IDF criteria [19], in contrast with our results of $40.7 \%, 67.5 \%$ and $67.0 \%$, respectively.

On the other hand, the relationship between MS and CRC surgical outcomes, recurrence and survival has been a source of disagreement with discording studies being published over the time.

For instance, a study from 2010 showed that the presence of metabolic syndrome was associated with a significant increase of hepatic metastasis and tumor recurrence [12]. In the same year another prospective study from Thailand peremptorily concluded that MS was an independent rick factor for postoperative complications and longer hospital stay in CRC patients submitted to surgery, with a 30 days follow-up [13]. On the other hand, in 2013, a retrospective cohort investigation concluded that MS had no influence on recurrence and overall survival of CRC patients, perhaps explained by the combined effects of elevated blood glucose and hypertension and the protective effect of dyslipidemia, has proven in the same study [20]. Moreover, two survival analysis from 2016 were able to, again, prove a deleterious effect of MS. On one of them, a prospective study involving 1318 CRC patients, it was proved that MS, specially hyperglycemia, were robust predictors of CRC mortality [21]. On the other one, from October 2016, patients were divided into 4 categories (defined by the presence of MS and/or obesity) and, as a result, the group with MS and obesity combined obtained a worse survival, overall and CRC related [22].

The pointed mechanism for this interaction might be explain by several theories: first, the insulin-resistant state present in MS influences an abnormal metabolism in adipocytes (especially visceral fat adipocytes) with subsequent increase in levels of Interleukin-6 and tumor necrosis factor- $\alpha$ (both pro-inflammatory) and low levels of adiponectin (protective adipokine) leading to an excessive systemic inflammatory response. Secondly, MS has been correlated with a situation of impaired microvascular circulation, which may cause diminished perfusion and poor tissue healing. And finally, alterations in polymorphonuclear cells has been noticed in patients with MS, which might be caused by the low levels of Leukotriene B4, essential in these cells function, leading this way to alterations in innate immune defense [13].

In our study there was no statistically significant influence of any of the MS definitions or it's components on the studied outcomes (no $\mathrm{p}$ value $<0.05$ ), and the only finding that proves influence of HDL-cholesterol (by ATPIII definition) with 30 days morbimortality and with Clavien-Dindo Classification Grade appears to us a statistical finding instead of a valuable finding concerning the context.

\section{Conclusion}

This study seems to indicate that there is no apparent association between MS, in its different definitions and components, and CRC surgical outcomes (reintervention, readmission, dehiscence and morbimortality) at 30 days.

While a deeper understanding of this relationship could lead to a better clinical management, data remains inconclusive. The question of whether or not a better control of metabolic status could improve CRC patients' prognosis waits for further studies with larger sample sizes and longer follow-up timings.

\section{Conflicts of interest}

None. 


\section{Funding information}

No funding.

\section{References}

[1] Pais R, Silaghi H, Silaghi AC, Rusu ML, Dumitrascu DL. Metabolic syndrome and risk of subsequent colorectal cancer. World J Gastroenterol 2009;15(41):51418.

[2] Grundy SM, Cleeman JI, Daniels SR, Donato KA, Eckel RH, Franklin BA, et al. Diagnosis and management of the metabolic syndrome: an American Heart Association/National Heart, Lung, and Blood Institute scientific statement. Circulation 2005;112(17):2735-52, doi:http://dx.doi.org/10.1161/ CIRCULATIONAHA.105.169404.

[3] Expert Panel on Detection, Evaluation and Treatment of High Blood Cholesterol in Adults. Executive summary of the third report of the National Cholesterol Education Program (NCEP) expert panel on detection, evaluation, and treatment of high blood cholesterol In adults (Adult treatment panel III). JAMA 2001;285(19):2486-97.

[4] Alberti KG, Zimmet P, Shaw J. Metabolic syndrome-a new world-wide definition. a consensus statement from the international diabetes federation. Diabet Med 2006;23(5):469-80, doi:http://dx.doi.org/10.1111/j.14645491.2006.01858.x.

[5] Uzunlulu M, Telci Caklili O, Oguz A. Association between metabolic syndrome and cancer. Ann Nutr Metab 2016;68(3):173-9, doi:http://dx.doi.org/10.1159/ 000443743.

[6] Jaggers JR, Sui X, Hooker SP, LaMonte MJ, Matthews CE, Hand GA, et al. Metabolic syndrome and risk of cancer mortality in men. Eur J Cancer 2009;45 (10):1831-8, doi:http://dx.doi.org/10.1016/j.ejca.2009.01.031.

[7] Feakins RM. Obesity and metabolic syndrome: pathological effects on the gastrointestinal tract. Histopathology 2016;68(5):630-40, doi:http://dx.doi. org/10.1111/his.12907.

[8] Esposito K, Chiodini P, Capuano A, Bellastella G, Maiorino MI, Rafaniello C, et al. Colorectal cancer association with metabolic syndrome and its components: a systematic review with meta-analysis. Endocrine 2013;44(3):634-47, doi: http://dx.doi.org/10.1007/s12020-013-9939-5.

[9] Ahmed RL, Schmitz KH, Anderson KE, Rosamond WD, Folsom AR. The metabolic syndrome and risk of incident colorectal cancer. Cancer 2006;107 (1):28-36, doi:http://dx.doi.org/10.1002/cncr.21950.

[10] GLOBOCAN. Estimated Cancer Incidence, Mortality and Prevalence Worldwide in 2012. International Agency for Research on Cancer; 2012 [Internet]. 2012. Available from: http://globocan.iarc.fr/.

[11] Ahmadi A, Noroozi M, Pourhoseingholi MA, Hashemi-Nazari SS. Effect of metabolic syndrome and its components on survival in colorectal cancer: a prospective study. J Renal Injury Prev 2015;4(1):15-9, doi:http://dx.doi.org/ 10.12861/jrip.2015.05.

[12] Shen Z, Ye Y, Bin L, Yin M, Yang X, Jiang K, et al. Metabolic syndrome is an important factor for the evolution of prognosis of colorectal cancer: survival, recurrence, and liver metastasis. Am J Surg 2010;200(1):59-63, doi:http://dx. doi.org/10.1016/j.amjsurg.2009.05.005.

[13] Lohsiriwat V, Pongsanguansuk W, Lertakyamanee N, Lohsiriwat D. Impact of metabolic syndrome on the short-term outcomes of colorectal cancer surgery. Dis Colon Rectum 2010;53(2):186-91, doi:http://dx.doi.org/10.1007/ DCR.0b013e3181bdbc32.

[14] De Raet J, Delvaux G, Haentjens P, Van Nieuwenhove Y. Waist circumference is an independent risk factor for the development of parastomal hernia after permanent colostomy. Dis Colon Rectum 2008;51(12):1806-9, doi:http://dx. doi.org/10.1007/s10350-008-9366-5.

[15] Kartheuser AH, Leonard DF, Penninckx F, Paterson HM, Brandt D, Remue C, et al. Waist circumference and waist/hip ratio are better predictive risk factors for mortality and morbidity after colorectal surgery than body mass index and body surface area. Ann Surg 2013;258(5):722-30, doi:http://dx.doi.org/ 10.1097/SLA.0b013e3182a6605a.

[16] Rullier E, Laurent C, Garrelon JL, Michel P, Saric J, Parneix M. Risk factors for anastomotic leakage after resection of rectal cancer. Br J Surg 1998;85(3):3558, doi:http://dx.doi.org/10.1046/j.1365-2168.1998.00615.x.

[17] Govaert JA, Lijftogt N, van Dijk WA, Tseng LN, Liem RS, Tollenaar RA, et al. Colorectal cancer surgery for obese patients: financial and clinical outcomes of a Dutch population-based registry. J Surg Oncol 2016;113(5):489-95, doi: http://dx.doi.org/10.1002/jso.24187.

[18] Dindo D, Demartines N, Clavien PA. Classification of surgical complications: a new proposal with evaluation in a cohort of 6336 patients and results of a survey. Ann Surg 2004;240(2):205-13.

[19] Santos AC, Barros H. Impact of metabolic syndrome definitions on prevalence estimates: a study in a Portuguese community. Diabetes Vasc Dis Res 2007;4 (4):320-7, doi:http://dx.doi.org/10.3132/dvdr.2007.059.

[20] Yang Y, Mauldin PD, Ebeling M, Hulsey TC, Liu B, Thomas MB, et al. Effect of metabolic syndrome and its components on recurrence and survival in colon cancer patients. Cancer 2013;119(8):1512-20.

[21] Peng F, Hu D, Lin X, Chen G, Liang B, Zhang H, et al. Preoperative metabolic syndrome and prognosis after radical resection for colorectal cancer: the Fujian prospective investigation of cancer (FIESTA) study. Int J Cancer 2016;139 (12):2705-13, doi:http://dx.doi.org/10.1002/ijc.30404.

[22] Cespedes Feliciano EM, Kroenke CH, Meyerhardt JA, Prado CM, Bradshaw PT, Dannenberg AJ, et al. Metabolic dysfunction, obesity, and survival among patients with early-stage colorectal cancer. J Clin Oncol 2016, doi:http://dx.doi. org/10.1200/JCO.2016.67.4473 Sep 6. pii: JCO674473. [Epub ahead of print]. 